\title{
Relating Academic Fields and Career Paths after College Education in Japan: Through Data Visualization with 2019 Survey Results
}

\author{
Nozomi Yoshida *, Rie Mori ${ }^{\dagger}$
}

\begin{abstract}
Since the deregulation of Standards for the Establishment of Universities in 1991 in Japan, diversification of faculty/department names has accelerated. The diversification made it difficult for college outsiders to correlate faculty/department names and academic fields, which might be one of the factors that hindered the college selections with perception of further career paths for university prospective students and career advisors in high schools. This study aims to find the efficient way in informing pre-higher education students of possible career-path selection after college education. In this study, we try to (A) visualize the characteristic of learning contents in each academic field using the name of major fields as a surrogate index for learning contents, and (B) examine the relationship between academic fields and career paths after college education. As a result, it shows (A) the characteristic of learning contents of academic fields by a morphological analysis and correspondence analysis on the name of major fields of academic degrees. In addition, it is revealed that (B) studying a specialized area of profession has been related to employment in a specific occupation and industry, while studying an interdisciplinary major has been related to employment in a wide variety of occupations. These results suggest the value of information provision on academic fields to be considered in the process of college selection. *
\end{abstract}

Keywords: nomenclature of major fields of academic degrees, major academic fields, career-path selection, education-career relationship, visualization

\section{Introduction}

\subsection{Diversification of faculty/department impacts major choice by high school students in Japan}

This study aims to find the effective way of career-path selection for high school students by (A) trying to visualize the characteristic of learning contents in each academic field, and (B) examining the relationship between academic fields and career paths after college education in Japan.

Since the deregulation of Standards for the Establishment of Universities in 1991 in Japan, diversification of faculty/department names has accelerated due to the individualization. In fact,

\footnotetext{
* University of the Ryukyus, Okinawa, Japan

$\dagger$ National Institution for Academic Degrees and Quality Enhancement of Higher Education, Tokyo, Japan

* This study is a revision and update of the paper of DSIR 2020 [1].
} 
names of faculties were originally limited to 29 , but by 1991, there were already 91 faculty names [2].

The problem impacts major choice by high school students in Japan, as is known from the research results that for prospective students, having a long-term vision for future career at the stage of college selection will provide clearer foresight for the majoring field and relevant aspired occupation, and will lead to higher satisfaction in college life and higher success rate in future job-hunting [3].

However, the results of questionnaire for career advisor in high schools show that they strongly require colleges to make, "faculty/department names understandable" as it is difficult to understand/foresee learning content and career paths after college education given the too much variety of academic fields appear in these names [4].

Given these findings, it is suggested that the diversification of faculty/department names might be one of the factors that hindered the college selections with perception of further career paths for university prospective students and career advisors in high schools.

In the United States, for example, College Board provides the website Big Future to guide career paths for prospective students, where they can relate academic majors and future professions. There appear 8 categories of academic major fields with 38 subcategories [5]. Individual higher education institutions are also making such efforts: Carleton College Career Center, for instance, visualizes the relationship between students' majors and their consequent career fields, in which 30 major fields appear [6].

Such studies about relationship between career paths after college education and the majoring fields have been conducted in European countries, as well [7][8]. A comparative study of career paths in England and the Netherlands finds that Dutch employers see the majoring field as a clear signal for college graduates' professional skills: the informatics major is taken as a reliable indicator of the IT-related-job readiness, for instance [7]. Another study on cases in Spain argues, likewise, that credentials in engineering and hard sciences give precise signal to employers about the skills of their holders [8].

Meanwhile, in Japan, faculty/department names have been highly diversified and more excessive diversification is observed with the nomenclature of major fields as is examined in following sections. As a consequence, it is becoming harder for higher-education stakeholders to relate credentials and the skills that the graduates are supposed to obtain. Therefore, it is considered to be necessary to clarify the learning content by academic field and, the relationship between academic fields and career paths after graduation to secure efficient and appropriate career-path selection.

\subsection{Previous trend of career paths after college education in occupation by aca- demic field}

A trend and change of career paths after college education in occupation by academic field of bachelor's degree between 1989 and 2010 based on the School Basic Survey indicates that except for studying a specialized area of profession in the field of Health Sciences, the relationship between academic fields and career paths post-graduate gradually diminishes and diverse in Japanese higher education [9]. As a typical example, post-graduate career pathway in the field of Science, the ratio of specialized / technical workers tends to decrease from 1989 to 2010 by about half (about $60 \%$ to $35 \%$ ), whereas the ratio of desk workers and sales clerks tend to increase. Similar trend is found in the field of Agriculture (about 55\% to 20\%). Furthermore, in the field of Education, the ratio of teachers tends to decrease from approximately $70 \%$ to below $50 \%$ over 
the decades. Interestingly, in the field of Home Economics, the ratio of nutritionist/dietitians is less than $10 \%$ in 1989 and increase to about 30\% in 2010. It might be explained that the number of nutritionist and dietitian training facilities increase from 1990 [10]. It is suggested that the diversification is caused by the transformation of a knowledge-based society, the progress of globalization, the collapse of lifetime employment, the rise in the university entrance rate, and the diversification of employment [9].

Although there has been a considerable discussion regarding the relationship between academic fields and career paths as seen above, about a decade has passed since the results of this longitudinal study were reported for the last time. Therefore, it is important to examine the relationship may or may not have changed state of, and trend in Japan.

\subsection{Purpose of this study and research question}

Given these problems, the purpose of this study is to find the effective way of career-path selection for university prospective students and career advisors in high schools by (A) trying to visualize the characteristic of learning contents by academic field, and (B) examining the relationship between academic fields and career paths after graduation in Japan. This study focuses on learning contents and career paths for bachelor's degree course.

Regarding the research question (A), this study employs the name of major fields as a surrogate index of learning contents by academic field. Nomenclature of major fields is, for example, like Bachelor (Literature), appeared in parentheses that follow each title showing the focal area of study that a student has performed. It is reviewed that formatted information for about knowledge and skill of students [11]. Before 1991, the nomenclature of all three kinds of academic degrees, bachelor's, master's and doctoral had been prescribed in the Standards for the Establishment of Universities. In case of bachelor's degree, for example, there had been 29 kinds of original names that showed individual majors such as Bachelor of Literature or Bachelor of Engineering had been prescribed ${ }^{\S}$ in the Standards. The variety of names of major disciplines employed by Japanese universities started to expand rapidly after 1991, then reached over 700 kinds of major fields as found by 2015 National Survey [12]. According to a series of studies that examines the variety of the names of major disciplines used nationwide, approximately $60 \%$ of 700 kinds of major fields are used by single universities [12][13][14]. Besides, Science Council of Japan Committee noted that approximately $50 \%$ of 700 kinds of names of major fields included 14 common keywords ${ }^{* *}$ related to increase an interdisciplinary major and a demand for new professions in society [2]. Some studies examine the factor of extreme variety of majors to suggest both academic field and year of establishment of a university contribute to the nomenclature diversification [12][13]. This study attempts to develop accumulated research and provide information for the enhancement of career guidance and education in high schools to secure efficient and appropriate career-path selection. It also aims to provide basic information of Japanese academic major fields for international comprehension.

\footnotetext{
$\S$ Note that 29 kinds of original majors are Literature, Education, Theology, Sociology, Liberal Arts, General Education, Social Sciences, Law, Political Science, Economics, Commerce, Business Administration, Science, Medicine, Dentistry, Pharmacy, Nursing, Health Sciences, Acupuncture and Moxibustion, Nutrition, Engineering, Design, Merchant Marine Science, Agriculture, Veterinary Medicine, Fisheries, Home Economics, Art, Physical Education.

**Note that 14 kinds of keyword are culture, information, social welfare, environment, international, business administration, human, health, policy management, medical, regional, sports, design, communication.
} 


\section{Method}

\subsection{Data}

\subsubsection{Nomenclature of major fields}

Regarding the research question (A), this study used the data of the nomenclature of major fields based on the 2019 National Survey implemented by the National Institution for Academic Degrees and Quality Enhancement of Higher Education (NIAD-QE) [15]. A total of 758 universities responded ( 85 national, 90 public and 583 private universities). The response rate was 96.1\%. The online questionnaire requires listing all names of academic fields and English version of degrees awarded by the university. Universities and departments that have stopped accepting students were asked to complete the questionnaire until final cohort of students complete the typical duration of study. All names of academic fields were classified and counted based on their academic discipline according to School Basic Survey' eleven academic discipline codes by the Ministry of Education, Culture, Sports, Science and Technology (MEXT) and published on the website (for eleven academic discipline codes see Table4 for details).

\subsubsection{Career paths after college education in occupations / industry classifications by academic field}

Regarding the research question (B), this study also used the data of new college graduates' career paths in the FY2019 School Basic Survey provided by the MEXT [16]. A total of 786 universities (86 national, 93 public and 607 private universities) responded. The School Basic Survey is a complete census conducted every year using questionnaires: it is part of national Fundamental Statistics and all universities are obligated to report information including career paths of their graduates. All graduates' career paths were classified into 12 occupations and 20 industry categories (Table1, Table3), and 11 academic categories, and published on the website. As for the classification of occupation, specialized/ technical workers have 14 kinds of sub-classification (Table2). In this study, following [9], each occupation / industry category with shares of less than $1 \%$ and $1-10 \%$ have been merged into categories of "less than $1 \%$ " and "1-10\%" respectively.

Table 1: Classification of occupation

\begin{aligned} & \hline 1 \multicolumn{1}{c}{ Occupation classification } \\ & 2 administrator \\ & 3 desk work \\ & 4 sales clerk \\ & 5 customer service \\ & 6 maintenance security \\ & 7 agriculture, forestry, fisheries \\ & 8 manufacturing line, laboring \\ & 9 transportation, machinery operation \\ & 10 construction, mining job \\ & 11 carrier, cleaning job \\ & 12 others \\ & \hline\end{aligned}


Table 2: Sub-classification of specialized / technical workers occupation

\begin{aligned} \hline & \multicolumn{1}{c}{ specialized / technical workers classification } \\ \hline 2 & researcher \\ 3 & technical in agriculture, forestry, fisheries \\ 4 & technical in manufacturing (other than development) \\ 5 & technical in architecture, civil engineering, surveying \\ 6 & technical in information processing, communication \\ 7 & other technologist \\ 8 & teaching \\ 9 & doctor / dentist, veterinary, pharmacist \\ 10 & health nurse, midwife, nurse \\ 11 & medical technician \\ 12 & other health/medical worker \\ 13 & art, photography, designer, music, show business \\ 14 & others \end{aligned}

Table 3: Classification of industry

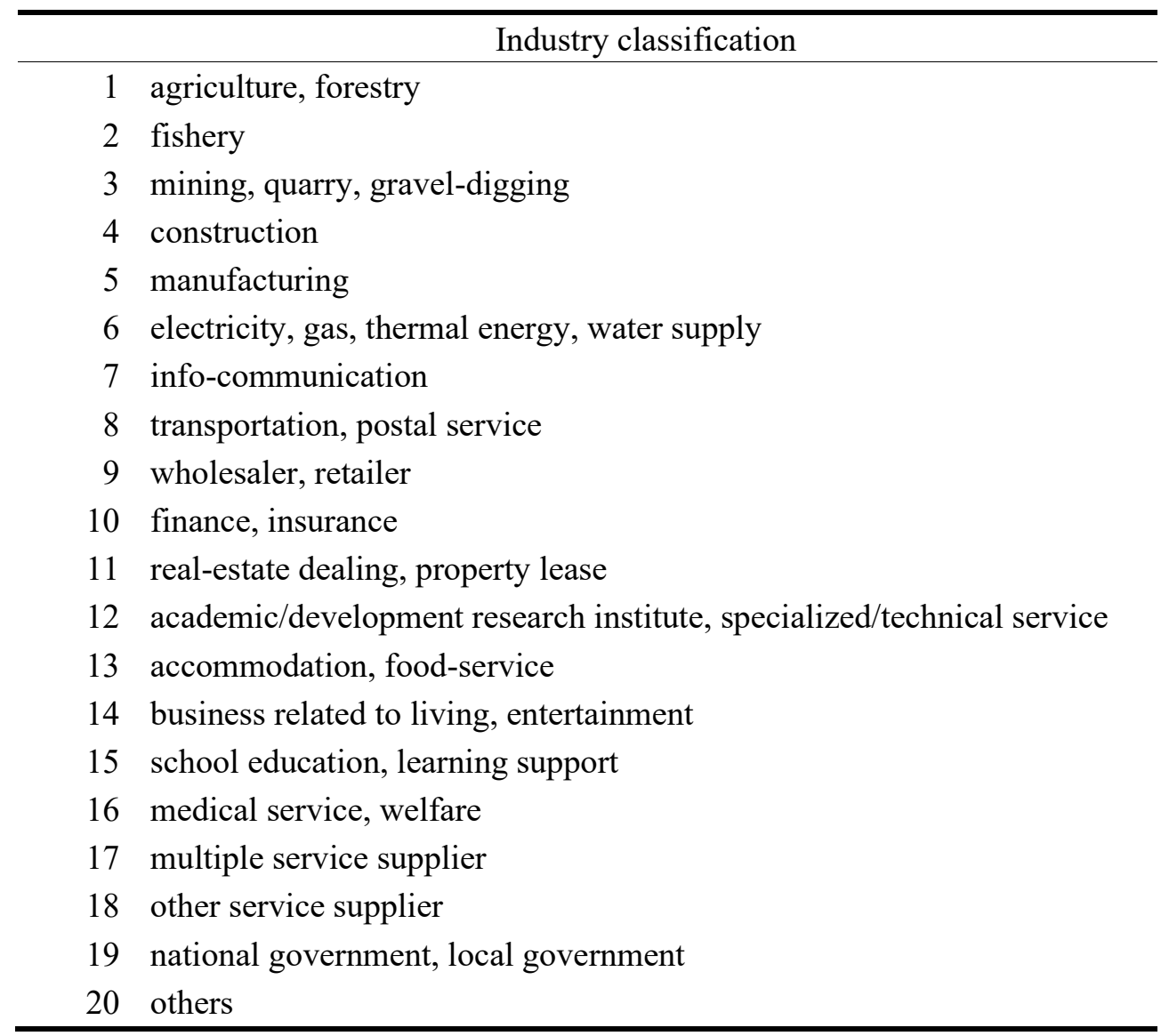




\subsection{Data analysis}

To examine the research question (A), this study employed a quantitative content analysis for nomenclature of major fields as a text using KH coder (Version 3.Alpha.17g) [17]. We attempted to use two types of methods to visualize characteristic of name of major field by academic field.

First, we calculated Jaccard index which is a statistic used for gauging the similarity and diversity of sample sets. The index takes a value from 0 to 1 , and the larger the value, the stronger the degree of cooccurrence of sample sets. Using the $\mathrm{KH}$ coder, we calculated the Jaccard index to analyze how similar texts in names of major fields are: when "A" is a set of texts with a certain variable and " $\mathrm{B}$ " is a set of all texts that include the word $\mathrm{x}$, the Jaccard index that shows how distinctive the word $\mathrm{x}$ is in a certain variable is calculated as follows:

$$
J(A, B)=\frac{|A \cap B|}{|A \cup B|}
$$

Second, we conducted a correspondence analysis using frequency of words to examine characteristic of learning contents in each academic field. Correspondence analysis is a method of data visualization that is applicable to cross-tabular data such as counts, compositions, or any ratio-scale data where relative values are of interest. Using the analysis, we can explore the correspondence between variables, i.e., academic fields, and words by plotting them on the same diagram. In the analysis, uncharacteristic words uniformly found in all parts are plotted near the origin $(0,0)$ (i.e., the point at which the ordinate and abscissa are both zero) whereas words having strong characteristics are located away from the origin. It shall be noted that in text-data analyses, contribution rate tends to appear low in percentage because the eigenvalue and contribution rate decrease as the number of item choices and categories increases [18].

\section{Results}

\subsection{Characteristic of learning contents by academic fields based on nomenclature of major fields}

As for the results of 2019, the number of degrees program and variety of names of major fields by academic field is shown in Table 4 . The total number of surveyed degree programs with independent name of major fields was 6164 . It is noted that there was no department categorized in the field of Merchant Marine Science.

A morphological analysis was conducted using 6164 text data of names of major fields, and 11058 words were extracted from the text data. The 10 most frequent words that appear in names of major fields in each academic field is shown in Table 5. The words that appear in the 29 kinds of original majors such as "literature", "business administration", or "science" tended to indicate high frequency in corresponding academic field. In addition, there were some other keywords, such as "human", "international" or "environment," that do not appear in traditional name but commonly used in multiple academic fields.

The top 10 characteristic words in each academic field are shown in Table 6. Although most of them are identical with 10 frequent words in Table 5, some commonly used words in multiple academic fields, such as "engineering" in the field of Science and Art or "science" in the field of Humanities, were not sought out as characteristic words. Therefore, the set of characteristic 
words is expected to show the nature of the academic field more precisely than that of frequent words. Meanwhile, a correspondence analysis was conducted on 77 frequent words that appear 50 times or more, focusing especially on 60 words for which the number of appearances appreciably changes among academic fields. Figure 1 shows the plot of correspondence analysis for academic fields ( $($ ) and words $(\bigcirc)$, such as "literature" and "science". In the Figure1, the words "design", "fine arts", "music" and "art" in the direction of "Art," for example, were most far away from the origin, which meant that the words appear more distinctively in the field of Art. The words "engineering" and "science" in the direction of "Engineering" were second most far away from the origin. The words such as "nursing", "dental surgery", "medical" and "pharmacy" were also second most far away from the origin in the direction of "Health Sciences," as well. On the other hand, the words "environment", "arts and sciences" and "information" were located near the origin along with "Home Economics" and "Others" indicating that they were commonly used in multiple academic fields.

In addition, it was also effective to see where each value of the variable was located. In Figure 1, "Art", "Engineering" and "Health Sciences" were far away from other values, but "Humanities", "Social Sciences" and "Education" were close to each other. This means that frequently occurring words were similar in the field of Humanities, Social Sciences and Education, which suggests that these three academic fields have greater continuity in learning contents. The fields of Sciences and Agriculture were also cohesive. As mentioned before, it is not uncommon for the contribution rate to be small in percent in text-data analyses. So this paper does not discuss the size of contribution rates.

Table 4: Number of degree programs and variety of names of major fields (NMFs) in each academic field

\begin{tabular}{lrr}
\hline Academic Fields & $\begin{array}{c}\text { Number of } \\
\text { degree program }\end{array}$ & $\begin{array}{c}\text { Number of } \\
\text { variety of NMFs }\end{array}$ \\
\hline Humanities & 919 & 194 \\
Social Sciences & 1246 & 212 \\
Science & 327 & 25 \\
Engineering & 1124 & 57 \\
Agriculture & 260 & 36 \\
Health Sciences & 902 & 103 \\
Merchant Marine Science & - & - \\
Home Economics & 225 & 63 \\
Education & 441 & 88 \\
Art & 258 & 33 \\
Others & 462 & 202 \\
\hline
\end{tabular}

Note: There was no department categorized as Merchant Marine Science. 
Table 5: The 10 most frequent words and frequency

\begin{tabular}{|c|c|c|c|c|c|}
\hline \multicolumn{2}{|c|}{ Humanities } & \multicolumn{2}{|l|}{$\begin{array}{l}\text { Academic field } \\
\text { Social Sciences }\end{array}$} & \multicolumn{2}{|c|}{ Sciences } \\
\hline literature & $408(.31)$ & business administration & $272(.16)$ & science & $266(.70)$ \\
\hline culture & $96(.07)$ & economics & $262(.16)$ & engineering & $29(.08)$ \\
\hline psychology & $88(.07)$ & social & $201(.12)$ & arts and sciences & $21(.06)$ \\
\hline international & $68(.05)$ & law & $153(.09)$ & life & $13(.03)$ \\
\hline human & 41(.03) & welfare & $122(.07)$ & applied & $5(.01)$ \\
\hline foreign & $39(.03)$ & commerce & 64(.04) & bio & $5(.01)$ \\
\hline science & $32(.02)$ & information & $63(.04)$ & agriculture & $5(.01)$ \\
\hline communication & $30(.02)$ & policy & $48(.03)$ & environment & $4(.01)$ \\
\hline english & $30(.02)$ & international & $46(.03)$ & information & $4(.01)$ \\
\hline social & $30(.02)$ & management & $30(.02)$ & bio & $2(.01)$ \\
\hline Total & $862(.66)$ & Total & $1261(.75)$ & Total & $354(.93)$ \\
\hline \multicolumn{2}{|c|}{ Engineering } & \multicolumn{2}{|l|}{ Agriculture } & \multicolumn{2}{|c|}{ Health Sciences } \\
\hline engineering & $977(.80)$ & agriculture & $143(.39)$ & nursing & $269(.21)$ \\
\hline information & $64(.05)$ & science & $39(.11)$ & therapy & $142(.11)$ \\
\hline arts and sciences & $42(.03)$ & bio & $32(.09)$ & science & $140(.11)$ \\
\hline science & $41(.03)$ & sources & $29(.08)$ & medicine & $82(.06)$ \\
\hline art & $17(.01)$ & veterinary medicine & $20(.05)$ & pharmacy & $78(.06)$ \\
\hline design & $8(.01)$ & marine & $15(.04)$ & health & $73(.06)$ \\
\hline architecture & $8(.01)$ & environment & $15(.04)$ & occupational & $55(.04)$ \\
\hline environment & $7(.01)$ & life & $9(.02)$ & medical & $48(.04)$ \\
\hline life & $7(.01)$ & fisheries & $7(.02)$ & clinical & $30(.02)$ \\
\hline computer & $5(.01)$ & arts and sciences & $6(.02)$ & dental surgery & $28(.02)$ \\
\hline Total & $1176(.96)$ & Total & $315(.84)$ & Total & $945(.73)$ \\
\hline \multicolumn{2}{|c|}{ Home Economics } & \multicolumn{2}{|l|}{ Education } & \multicolumn{2}{|l|}{ Art } \\
\hline nutrition & $79(.23)$ & education & $263(.45)$ & art & $137(.48)$ \\
\hline home economics & $48(.14)$ & child & $59(.10)$ & music & $48(.17)$ \\
\hline science & $41(.12)$ & science & $35(.06)$ & design & $37(.13)$ \\
\hline human life & $41(.12)$ & sport & $31(.05)$ & fine arts & $16(.06)$ \\
\hline health & $19(.05)$ & physical education & $29(.05)$ & engineering & $10(.04)$ \\
\hline environment & $17(.05)$ & health & $17(.03)$ & instrumental music & $7(.02)$ \\
\hline food & $18(.05)$ & human & $16(.03)$ & information & $5(.02)$ \\
\hline human & $14(.04)$ & development & $15(.03)$ & culture & $3(.01)$ \\
\hline child & $7(.02)$ & psychology & $10(.02)$ & education & $2(.01)$ \\
\hline design & $5(.01)$ & literature & $10(.02)$ & planning & $2(.01)$ \\
\hline Total & $289(.81)$ & Total & $485(.83)$ & Total & $267(.92)$ \\
\hline \multicolumn{2}{|c|}{ Others } & & & & \\
\hline science & $73(.10)$ & & & & \\
\hline international & $57(.07)$ & & & & \\
\hline human & $46(.06)$ & & & & \\
\hline engineering & $43(.06)$ & & & & \\
\hline liberal arts & $30(.04)$ & & & & \\
\hline information & $30(.04)$ & & & & \\
\hline sport & $27(.04)$ & & & & \\
\hline health & $27(.04)$ & & & & \\
\hline culture & $26(.03)$ & & & & \\
\hline environment & $23(.03)$ & & & & \\
\hline Total & $382(.47)$ & & & & \\
\hline
\end{tabular}

Note1: Numbers in parentheses on each word indicates ratio of words to total extracted words.

Note2: Numbers in parentheses on Total indicates cumulative ratio of the 10 words to total extracted words. Note 3: Words that appear in the 29 kinds of original majors presented in bold. Note 4: Words that appear in the 14 keywords presented in italics. 
Table 6: The top 10 characteristic words and Jaccard index

\begin{tabular}{|c|c|c|c|c|c|}
\hline \multicolumn{6}{|c|}{ Academic field } \\
\hline literature & .429 & business administration & .214 & science & .534 \\
\hline culture & .099 & economics & .209 & arts and sciences & .048 \\
\hline psychology & .092 & social & .153 & life & .037 \\
\hline international & .066 & law & .122 & applied & .015 \\
\hline foreign & .042 & welfare & .094 & bio & .014 \\
\hline human & .040 & commerce & .051 & physics & .006 \\
\hline english & .032 & information & .047 & sources & .006 \\
\hline communication & .032 & policy & .037 & astro & .003 \\
\hline humanities & .029 & international & .035 & atmospheric & .003 \\
\hline japanese & .027 & management & .024 & data & .003 \\
\hline \multicolumn{2}{|l|}{ Engineering } & \multicolumn{2}{|l|}{ Agriculture } & \multicolumn{2}{|c|}{ Health Sciences } \\
\hline engineering & .794 & agriculture & .528 & nursing & .297 \\
\hline information & .052 & bio & .119 & therapy & .157 \\
\hline arts and sciences & .035 & sources & .109 & medicine & .091 \\
\hline science & .034 & veterinary medicine & .077 & pharmacy & .087 \\
\hline architecture & .007 & science & .068 & health & .080 \\
\hline design & .007 & marine & .057 & science & .068 \\
\hline computer & .004 & environment & .046 & occupational & .061 \\
\hline system & .004 & life & .031 & medical & .053 \\
\hline technologists & .003 & fisheries & .027 & clinical & .033 \\
\hline clinical engineering & .002 & food & .019 & dental surgery & .031 \\
\hline \multicolumn{2}{|c|}{ Home Economics } & \multicolumn{2}{|l|}{ Education } & \multicolumn{2}{|l|}{ Art } \\
\hline nutrition & .310 & education & .562 & art & .474 \\
\hline home economics & .211 & physical education & .065 & music & .184 \\
\hline human life & .174 & sport & .065 & design & .100 \\
\hline science & .077 & child & .056 & fine arts & .061 \\
\hline health & .064 & science & .046 & planning & .008 \\
\hline environment & .059 & development & .034 & animation & .004 \\
\hline food & .040 & health & .033 & fashion & .004 \\
\hline human & .039 & human & .028 & film & .004 \\
\hline child & .028 & childhood care & .020 & voice performance & .004 \\
\hline design & .019 & school & .018 & visual & .004 \\
\hline \multicolumn{2}{|l|}{ Others } & & & & \\
\hline science & .099 & & & & \\
\hline international & .098 & & & & \\
\hline human & .082 & & & & \\
\hline liberal arts & .059 & & & & \\
\hline sport & .054 & & & & \\
\hline health & .052 & & & & \\
\hline information & .049 & & & & \\
\hline culture & .044 & & & & \\
\hline environment & .044 & & & & \\
\hline management & .038 & & & & \\
\hline
\end{tabular}

Note 1: The values indicate Jaccard index which takes a value from 0 to 1 . Note 2: Words that appear in the 29 kinds of original majors presented in bold.

Note 3: Words that appear in the 14 keywords presented in italics. 


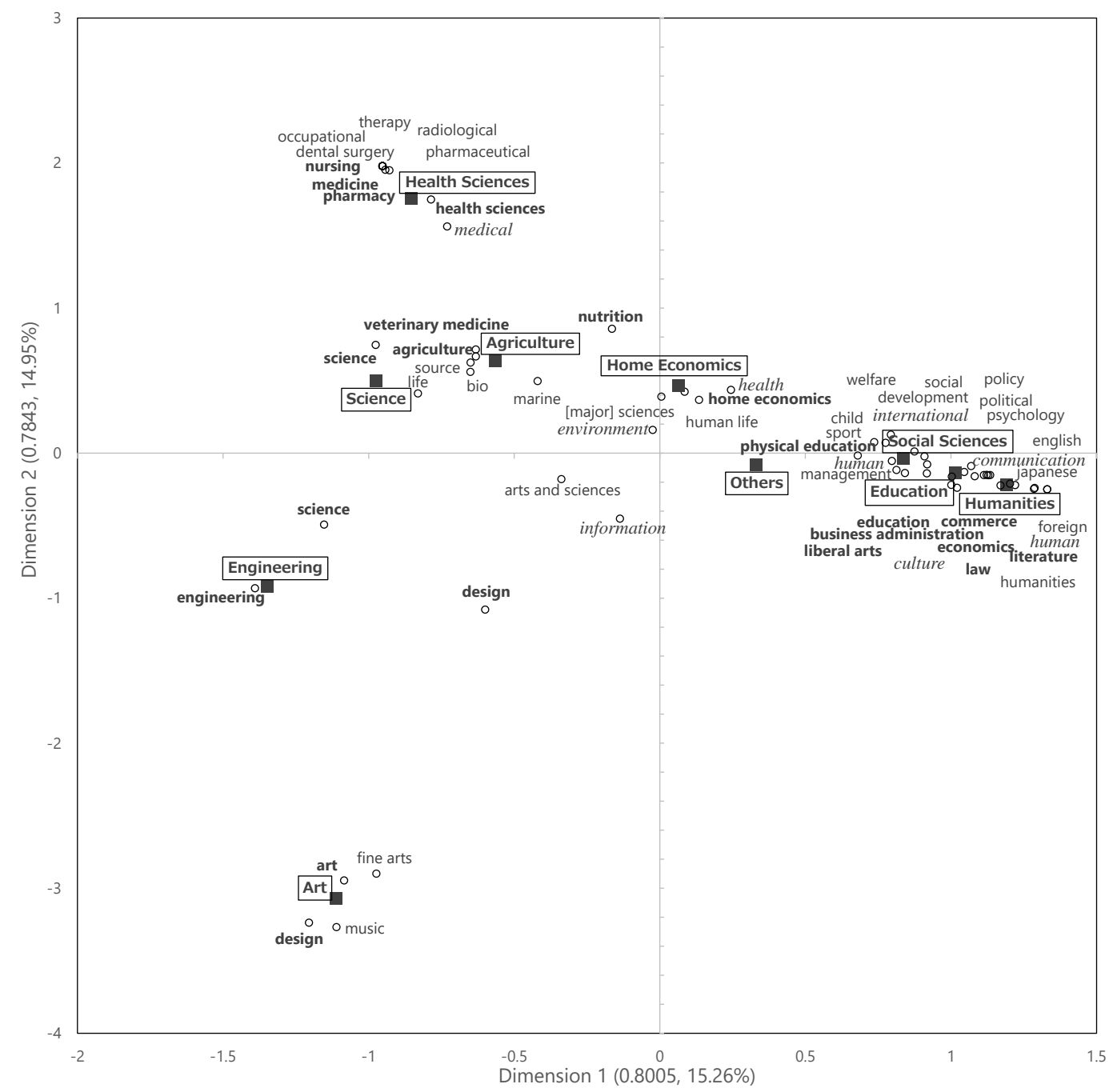

Note 1: Numbers in parentheses on $\mathrm{X}$ and $\mathrm{Y}$-axes indicate the eigenvalue and contribution rate respectively. Note 2: Words that appear in the 29 kinds of original majors presented in bold. Note 3: Words that appear in the 14 keywords presented in italics.

Figure 1: Plot of correspondence analysis of variable of academic field $(\mathbf{\square})$ and words $(\bigcirc)$

\subsection{Relationship between academic fields and career-paths after education}

The ratio of occupations, sub-classification of specialized / technical workers, and industries of new graduates by academic field is shown in Figure 2, 3 and 4 respectively.

In Figure 2, although the ratio of "specialized/technical workers", "desk work" and "sales clerk" were over $10 \%$ in every academic field, the trend differed by them. In field of $\mathrm{Hu}$ manities, the ratio of "desk work" and "sales clerk" were approximately $70 \%$, indicating they were main career paths in these fields. The same trend was found in the field of Social Sciences. On the other hand, in the field of Engineering and Health Sciences, the ratio of "specialized/technical workers" was approximately 80 to $90 \%$. It is noted that, in the field of Science, the ratio of "specialized/technical workers" has reached around $50 \%$, increased 
from 2010 (35\%) and getting closer to the level of $1989(60 \%)$, which is described in section 1.2 [9]. Meanwhile, in the fields of Agriculture and Education, the ratios of "specialized/technical workers" have increased from 2010, but they still have not reached the level of 1989, which is described in section 1.2 [9].

In Figure 3, there was range about $30 \%$ to $40 \%$ of ratio of "tech. in info. processing, communication" in the field of Humanities, Social Sciences, Engineering and Merchant Marine Science. In the field of Health Sciences, most of specialized / technical workers were particular health care worker such as "doctor / dentist, veterinary, pharmacist", "health nurse, midwife, nurse" and "medical technician". Similarly, a main specialized / technical worker was "teacher" in the field of Education, "art, photography, designer, music, show business" in the field of Art, and "other health/medical worker" like "nutritionist" and "dietician" in the field of Home Economics. It is noted that in comparison to the trend in 1989 and 2010, which is described in section 1.2, the ratio of nutritionist/dietitians has increased and reached around $50 \%$ in the field of Home Economics.

In Figure 4, although the ratio of "manufacturing", "info-communication" or "wholesaler, retailer" were over $10 \%$ in every academic fields except for the field of Education, the trend was highly different among them. In the field of Education, the ratio of "school education, learning support" was about $45 \%$. In the field of Health Sciences, the ratio of "medical service, welfare" was overwhelmingly large. In the other academic fields, there was a specific industry like "finance, insurance" in field of Social Sciences, "school education, learning support" in the field of Science, "construction" in the field of Engineering, "national gov., local gov." in the field of Agriculture, "transportation, postal service" in the field of Marchant Marine Science, "accommodation, food-service" in the field of Home Economics and, "academic/development research institute" in the field of Art.

These results indicate that studying a specialized area of profession is related to employment in a specific occupation and industry, while studying an interdisciplinary major is related to employment in a wide variety of occupations. It is suggested that there was a specific trait between academic fields and career paths after graduation that university prospective students and advisors at high schools can take into consideration.

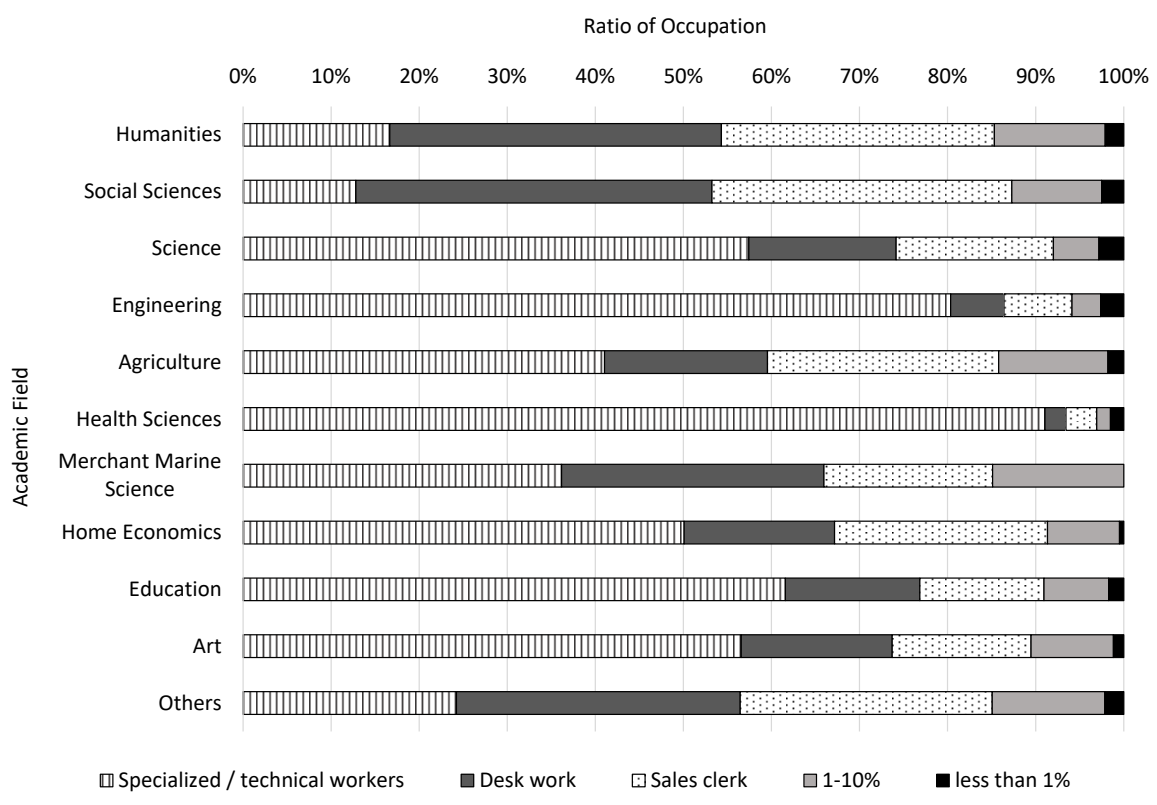

Figure 2: The ratio of occupations by academic field 


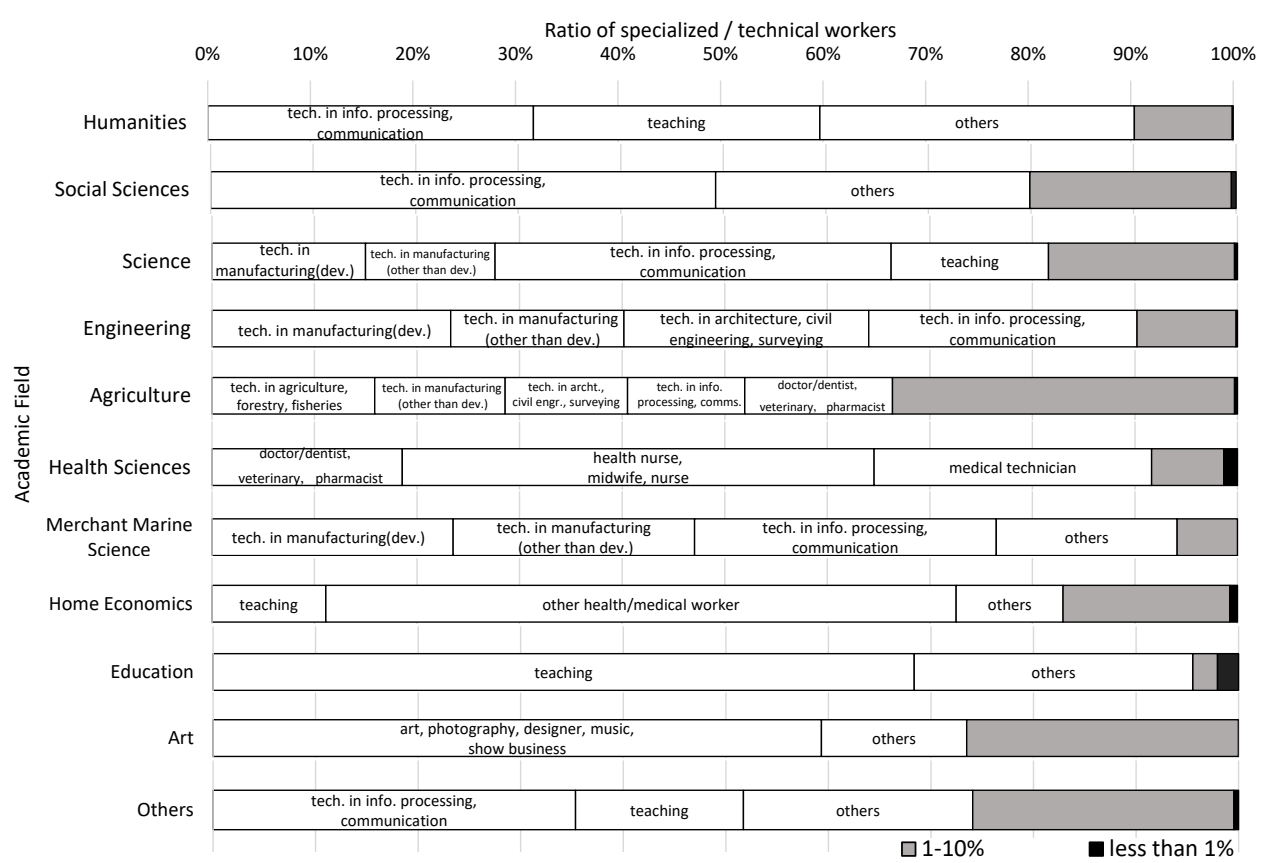

Note: Some occupations are presented with abbreviation, see Table 2 for detail.

Figure 3: The ratio of specialized / technical workers by academic field

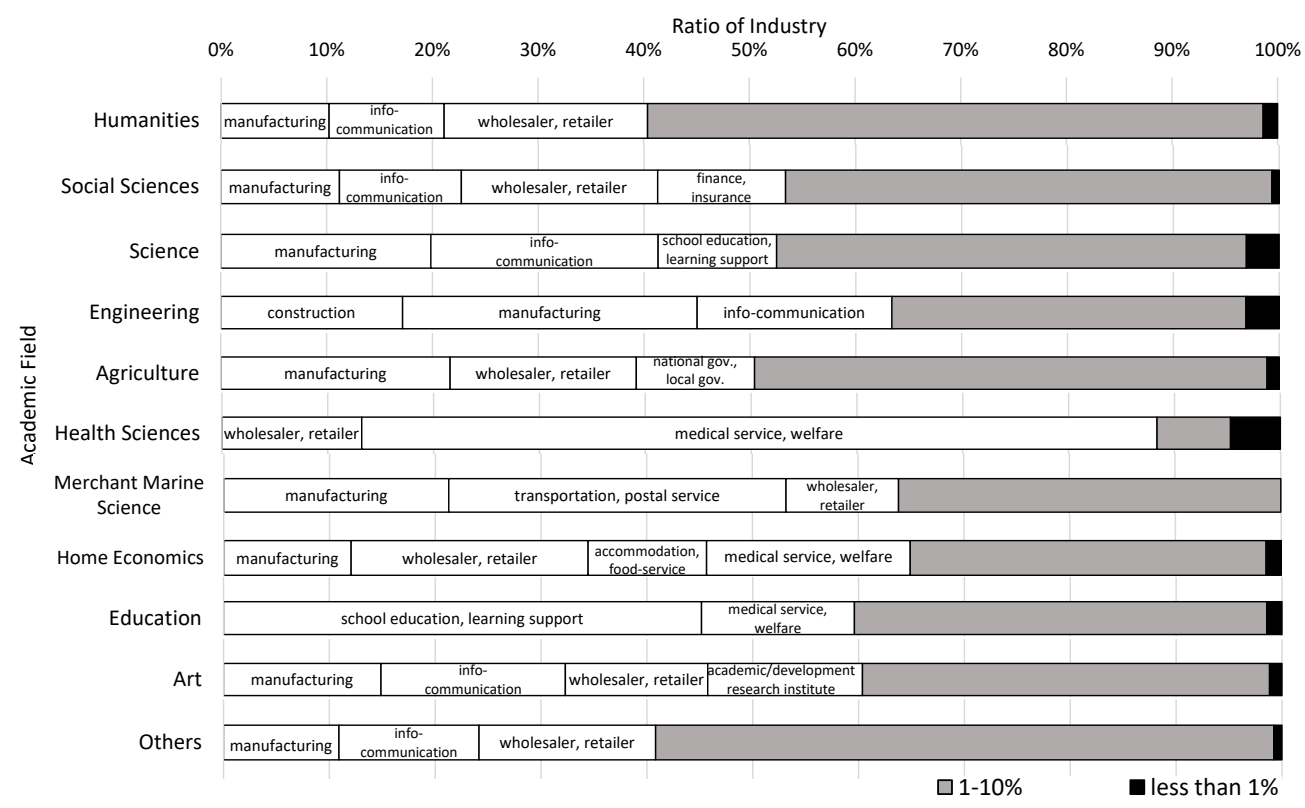

Note: Some industries are presented with abbreviation, see Table 3 for detail.

Figure 4: The ratio of industries by academic field 


\section{Discussion}

\subsection{Visualization of characteristic learning contents by academic fields based on nomenclature of major fields}

In this research, the nomenclature of major fields which represents the focal area of students' study is used as a surrogate index to characterize learning contents in each academic field. The results of morphological analysis and correspondence analysis showed the characteristic of learning contents by academic field.

The words as the 29 kinds of original majors were mainly found in top 10 frequent and characteristic words, suggesting the central tendency of learning contents in each academic field might be common among universities from 1991. In addition, 14 other keywords were found in multiple academic fields, implying a demand for new professional skills in society, while interdisciplinary/comprehensive education beyond disciplinary boundaries still exist as previously reported [2].

The plot of correspondence analysis showed the similarity and diversity among academic fields. In particular, the field of Art, Engineering and Health Sciences tended to be scattered far away from the origin along with some specific vocabulary, whereas the field of Humanities, Social Sciences, and Education tended to gather in the same direction along with some specific words. It is demonstrated that some academic fields require learning in highly specific contents while others provide contents more coherent to each other.

Based on these results, it is possible to envision how "specific" the learning contents are in some academic fields, and how "interdisciplinary" they are in other academic fields. Visualization of learning contents by academic fields may help university prospective students and advisers foresee or communicate what higher education majors look like at early stages of career guidance.

\subsection{Current status and trend of the relationship between academic field and ca- reer paths after education}

As examined in the previous chapter, different academic fields lead college graduates to occupation and industry with diversified distribution. Comparing the recent distribution in 2019 to those in 1989 and 2010, the ratios of career paths in the specialized/technical category in the fields of Science, Agriculture and Education in 2019 tend to be lower than those in 1989 but higher than those in 2010. It is assumed that the decrease of specialized/technical workers in 2010 was caused by the Great Recession that was in place between 2007 and 2010. The results of 2019 survey are thought to be showing the effects of the recovery of Japanese economy. Another trend is also seen with the ratio of nutritionist/dietitians in the field of Home Economics that has been increasing since 1989. Such a strong orientation is also observed in the field of Health Science.

In the distribution of industry, while some industry was commonly selected as post-graduate career paths in multiple academic fields, other industries were selected only in a specific academic field. In the field of Humanities, Social sciences, Science, Agriculture, and Other, industry of less than $10 \%$ exist about $50 \%$ to $60 \%$, indicating career paths for industry had diversification in these academic fields. If it can be said that the result was influenced by the individualization of universities, the change in the relationship between the university and the labor market, and the environment surrounding the university [9], it is important that a longitudinal study will be 
conducted to follow trend and change of the relationship between academic field and career paths after education.

\subsection{Limitation and further study}

There are some major limitations in this study that could be addressed in future research. First, in the text analysis used this study, words with low frequency of occurrence will be ranked lower. Therefore, there is a possibility that the names of major fields used only in a single university may not appear as a feature word. This kind of nomenclature of major fields may be associated with difficult faculty / department names to understand / foresee learning content and career paths after college education. In order to visualize the characteristics of these, it is necessary to use text mining indicators and methods that do not depend on the frequency of occurrences.

Secondly, this study only covers the data of career paths after education by academic fields in Japanese university, and it will be necessary to verify, in the international comparison research, whether the results in this study are the same of conditions in other nations' university.

As noted earlier, some studies examine the factor of extreme variety of majors to suggest that both academic field and year of establishment of a university contribute to the nomenclature diversification [12][13]. It is presumable that the factor of types of universities would relate in career paths after graduation too. This study did not examine such a factor, and it can be deemed to be the third point of the limitation in this study. Therefore, in further research, the authors aim to examine the relationship between academic fields and career paths by type of the university.

\section{Conclusion}

This study aims to find the effective way of college selection for high school students with post-graduate career paths into consideration by (A) trying to visualize the characteristic of learning contents in each academic field, and (B) examining the relationship between academic fields and career paths after graduation in Japan. The data set from two National Surveys conducted NIAD-QE and MEXT respectively, were analyzed to examine research questions. The results reveal following facts: regarding the research question (A), it is viable to visualize how different / close to each other the academic fields are, by text-analyses of the wide variety of names of major fields. As for the research question (B), studying in a specialized area of profession may lead students to employment in a specific occupation or industry, while studying in an interdisciplinary major may lead them to employment in a wide variety of occupations.

\section{References}

[1] N. Takahashi, and R. Mori, "Relationship between academic fields and career paths after college graduation in Japan," Proc. 2020 9th International Congress on Advanced Applied Informatics (IIAI-AAI), 2020, pp. 838-839.

[2] Science Council of Japan Committee for university education's quality assurance initiatives by field, "Review for future vision on nomenclature of major disciplines in Japan,” Report on discussions, September 2014. (in Japanese)

[3] DISCO Inc., "Survey on university entrance and employment ," Careertas Research, pp. 1-12, Mar. 2018. (in Japanese); https://www.disc.co.jp/press_release/5768/ (accessed 12 Dec. 2020). 
[4] Recruit, "Survey on high school career guidance and career education," Recruit Marketi ng Partners Co., Ltd., Jan. 2017. (in Japanese); http://souken.shingakunet.com/research/20 10/07/post-5cb6.html (accessed 12 Dec. 2020).

[5] College Board, Big Future; https://bigfuture.collegeboard.org/(accessed 06 Apr. 2021).

[6] Carleton Career Center, Carleton College Career Paths; https://apps.carleton.edu/career/ visualize/(accessed 06 Apr. 2021).

[7] V. Di Stasio, and H.G.vande Werfhorst, "Why Does Education Matter to Employers in Different Institutional Contexts? A Vignette Study in England and the Netherlands" Soci al Forces, 95 (1): pp. 77-106, 2016.

[8] L. Ortiz, and J. Rodriguez-Menés, "The Positional Value of Education and its Effect on General and Technical Fields of Education: Educational Expansion and Occupational Re turns to Education in Spain” European Sociological Review, 32(2): pp. 216-37, 2016.

[9] T. Kawashima, "The Changing Labor Market and Reform of University Education" The Japanese journal of labour studies, vol. 54(12), pp. 19-30, 2012. (in Japanese)

[10] M. Suzuki, "Diversity and variation of the institiutions for training dietitians and registrered dietitians" Annual Bulletin, Graduate School of Education, Tohoku University, vol 58 (1), pp. 33-56, 2009. (in Japanese)

[11] M. Kaneko, "Challenges to Academic Degree System in the Mobile and Knowledge-Centered Society," The Journal on Academic Degrees of National Institution for Academic Degrees and University Evaluation: Research in Academic Degrees, no. 17, pp. 5-23, 2003. (in Japanese)

[12] N. Takahashi, and R. Mori, "The Diversification of Nomenclature of Academic Degrees in Japanese Higher Education: Current State and Transition as found by 2015 National Survey," RCUS, University of Tsukuba: University Studies, vol. 45, pp. 3-15, 2018. (in Japanese)

[13] Y. Hamanaka, "Excessive variegation of nomenclature of major disciplines in academic degrees," IDE: The Contemporary Higher Education, vol. 473, pp. 62-68, 2005. (in Japanese)

[14] R. Mori, "Excessive variegation of nomenclature of major disciplines in academic degrees -Current state of Japan and U.S.," Handout of the 1st review meeting for the role of nomenclature of major disciplines, December 2010. (in Japanese).

[15] National Institution for Academic Degrees and Quality Enhancement of Higher Education, "The 2019 National Survey for the nomenclature of major fields," Nov. 2020 (in Japanese); https://www.niad.ac.jp/publication/gakui/meishou.html (accessed 12 Dec. 2020).

[16] Ministry of Education, Culture, Sports, Science and Technology, "The FY2019 School Basic Survey,” Dec. 2019 (in Japanese); https://www.e-stat.go.jp/ (accessed 12 Dec. 2020).

[17] K. Higuchi, "Quantitative Text Analysis for Social Research: Toward Succession and Development of Content Analysis," Nakanishiya-shuppan, Inc., 2014. (in Japanese) 
[18] N. Ohsumi, "Correspondence analysis method / quantification method type III concept", 2005. (in Japanese); http://www.ai.u-hyogo.ac.jp/ arima/ca.pdf (accessed 12 Dec. 2020). 